\title{
Using music to study the evolution of cognitive mechanisms relevant to language
}

\author{
Aniruddh D. Patel ${ }^{1}$ \\ Published online: 1 July 2016 \\ (C) Psychonomic Society, Inc. 2016
}

\begin{abstract}
This article argues that music can be used in crossspecies research to study the evolution of cognitive mechanisms relevant to spoken language. This is because music and language share certain cognitive processing mechanisms and because music offers specific advantages for cross-species research. Music has relatively simple building blocks (tones without semantic properties), yet these building blocks are combined into rich hierarchical structures that engage complex cognitive processing. I illustrate this point with regard to the processing of musical harmonic structure. Because the processing of musical harmonic structure has been shown to interact with linguistic syntactic processing in humans, it is of interest to know if other species can acquire implicit knowledge of harmonic structure through extended exposure to music during development (vs. through explicit training). I suggest that domestic dogs would be a good species to study in addressing this question.
\end{abstract}

Keywords Music cognition · Language evolution · Comparative psychology

Instrumental music and spoken language have many obvious differences, ranging from the acoustic structure of their fundamental building blocks (e.g., tones vs. phonemes or syllables) to the kinds of meanings that sequences convey to listeners (Slevc \& Patel, 2011). Yet a growing body of research suggests that the cognitive processing of instrumental music and of language has more in common than one might initially suspect. (Henceforth in this article, music refers to

Aniruddh D. Patel

a.patel@tufts.edu

1 Department of Psychology, Tufts University, Medford, MA, USA instrumental music, and language refers to ordinary language, i.e., not poetry, chant, or other stylized forms). Hidden links between musical and linguistic cognition have been found at several levels of language processing, including syntactic, semantic, prosodic, phonological, and affective (e.g., Flaugnacco et al., 2015; Habib et al., 2016; Koelsch et al., 2004; Koelsch, Gunter, Wittfoth, \& Sammler, 2005; Kunert, Willems, Casasanto, Patel, \& Hagoort, 2015; Kunert, Willems, \& Hagoort, 2016; Lima \& Castro, 2011; Liu, Patel, Fourcin, \& Stewart, 2010; Musso et al., 2015; Patel, Peretz, Tramo, \& Labreque, 1998; Slevc, Rosenberg, \& Patel, 2009; Thompson, Schellenberg, \& Husain, 2004; for recent debate, see Collins, Tillmann, Barrett, Delbé, \& Janata, 2014; Kunert \& Slevc, 2015; Peretz, Vuvan, Lagrois, \& Armony, 2015; Tillmann \& Bigand 2015).

The purpose of this short essay is to point out one implication of these connections for research on the evolution of spoken language processing. This is the idea that music can be used in comparative (cross-species) studies to study the evolution of cognitive mechanisms involved in language. Thus, for example, if a specific aspect of music processing is known to have a (nontrivial) link to linguistic syntactic processing, then one can study this aspect of music processing in other species to gain insight into the evolutionary precursors of syntactic processing. This is of interest because music provides certain advantages for cross-species research. The raw materials of music (individual tones) can be relatively simple stimuli, and neuroscientific and behavioral research suggests that pitch perception of individual tones is similar in humans and other mammals (Bendor \& Wang, 2005; Song, Osmanski, Guo, \& Wang, 2016). Tones lack the acoustic complexity of spoken syllables and the semantic properties of words, yet in musical contexts humans perceive tones in terms of rich hierarchical relations and implicit structural norms (Jackendoff \& Lerdahl, 2006; Krumhansl, 2015; Patel, 2003, 2008). Children 
learn these norms similarly to how they learn linguistic structural norms (i.e., without formal instruction).

To take one example, Corrigal and Trainor (2014) showed that children who grow up hearing Western tonal music can identify out-of-key chords in novel melodies by the age of 5 years. Interestingly, the researchers also showed that at an even slightly earlier age (average 4.5 years old), Western children show an event-related potential (ERP) response to such chords in passive listening tasks (e.g., while watching a silent movie). In contrast, 8-month-old infants do not appear to be sensitive to musical key structure (Trainor \& Trehub 1992), which shows that this sensitivity is not hard wired at birth. Instead, the sensitivity likely reflects implicit knowledge that develops though exposure to the native musical system. The acquisition of this knowledge does not require formal musical training and may rely instead on statistical learning, a cognitive mechanism thought to span both music and spoken language. Infants, for example, have been shown to extract statistical regularities from both syllable and tone sequences (Saffran, Aslin, \& Newport, 1996; Saffran, Johnson, Aslin, \& Newport, 1999). Although statistical learning may help the human mind acquire implicit knowledge of the norms of harmonic structure, evidence from behavioral and neural studies suggests that the processing of harmonic structure by adults involves hierarchical processing (e.g., Koelsch, Rohrmeier, Torrecuso, \& Jentschke, 2013; Lerdahl \& Krumhansl, 2007; cf. Rohrmeier, 2011), which overlaps and interacts with the processing of grammatical relationships in language (for empirical evidence, see Fedorenko, Patel, Casasanto, Winawer, \& Gibson, 2009; Koelsch, Gunter, et al., 2005; Kunert et al., 2015, 2016; Musso et al., 2015; Slevc et al., 2009; Van de Cavey \& Hartsuiker, 2016).

It is thus of considerable interest to know if other species can acquire sensitivity to harmonic structure in music. This would provide a novel way to study cognitive and neural mechanisms relevant to the evolution of linguistic syntactic processing (cf. Fitch, 2014). There is prior work with nonhuman animals that has examined syntactic processing using nonlinguistic sounds (e.g., Gentner, Fenn, Margoliash, \& Nusbaum, 2006; ten Cate \& Okanoya, 2012; cf. Ravignani, Sonnweber, Stobbe, \& Fitch, 2013), but this work often relies on extensive training, which differs from the spontaneous acquisition of linguistic and musical structural knowledge observed in humans. There is thus an untapped line of crossspecies research exploring the extent to which other animals, like humans, can acquire implicit knowledge of musical harmonic structure through extended exposure to music (i.e., over several years, spanning birth to adulthood.)

I would like to suggest that one species that may prove particularly useful in addressing this issue is the domestic $\operatorname{dog}$ (Canis familiaris). Dogs have lived with humans for thousands of years and attend to human behavior and social cues to a degree that can surpass chimpanzees (Kirchofer,
Zimmermann, Kaminski, \& Tomasello, 2012; Rosati, Santos, \& Hare, 2010). In the West, dogs are often raised in households where music is frequently heard, alongside human children who spontaneously acquire implicit knowledge of musical harmonic structure based on this exposure. Despite the growing number of music CDs for dogs (which are premised on the idea that they experience music in a way similar to how we do), we actually have no idea how dogs perceive music. The hearing range and frequency resolution of dogs seems sufficient for basic music perception (Anrep, 1920; Heffner, 1983). Furthermore, dogs appear to be significantly superior to monkeys in auditory short-term memory abilities, which would facilitate the learning of musical patterns (Kuśmierek, Kowalska, \& Mishkin, 1999; Kuśmierek \& Kowalska, 1998; Scott, Mishkin, \& Yin, 2012). Do dogs (like humans) develop implicit knowledge of musical harmonic structure through exposure to music over several years? (If not, our music may sound to them like atonal music sounds to us.)

One way to address this question is to study neural responses to out-of-key chords in dogs using ERP, as Corrigal and Trainor (2014) did with young children. Such experiments require only passive listening (with no behavioral response). Out-of-key chords produce specific ERP responses in humans, and one could look for analogs of these responses in dogs. (Recent studies have shown that the ERP methodology can be used with awake dogs, e.g., Howell, Conduit, Toukhsati, \& Bennett, 2012; Kujala et al., 2013; Törnqvist et al., 2013.) Another option for neural studies is fMRI. This technique has recently been used to study voice-sensitive cortical regions in awake, unanesthetized dogs trained to lie still in an MRI scanner (Andics, Gácsi, Faragó, Kis, \& Miklósi, 2014). Using the canine auditory fMRI method pioneered by Andics et al., one could determine if dogs, like humans, show increased activity in inferior frontal brain regions when hearing music that is harmonically complex versus simple, which would suggest cognitive processing of harmonic structure (cf. Tillmann et al., 2006; Patel, 2003). (Another interesting use of fMRI would be to examine activity in the mesolimbic reward pathway when dogs hear music that is frequently played in their households, to determine if they, like their owners, derive pleasure from such music; cf. Zatorre \& Salimpoor, 2013).

Of course, behavioral studies would also be important (e.g., discrimination studies in which dogs are tested for their ability to respond differentially depending on whether a novel musical sequence contains one or more out-of-key chords). Demonstration of sensitivity to harmonic structure in dogs would be a first step toward investigating whether they, like humans, develop the ability to process music hierarchically through extended exposure to it. Such investigations of hierarchical processing need not only focus on pitch structure but could also examine rhythmic processing (e.g., the perception 
of metrical structure; Fitch, 2013; Honing, Merchant, Háden, Prado, \& Bartolo, 2012; Schachner, Brady, Pepperberg, \& Hauser, 2009). Given the rising amount of cognitive research with dogs, including studies of how they perceive human speech, faces, and emotional expressions (e.g., Huber, Racca, Scaf, Virányi, \& Range, 2013; Müller, Schmitt, Barber, \& Huber, 2015; Ratcliffe \& Reby, 2014; cf. Stewart et al., 2015), and how they respond vocally to human music (Yuan, Rosenberg, \& Patel, 2016), hopefully research on canine music perception is not too far in the future.

Taking a step back, the larger point is that studies of language evolution would benefit from knowing whether nonhuman animals, like human children, can acquire implicit knowledge of the structural rules of a language-like communication system via extended exposure to that system (without explicit training) during development. Instrumental music provides an opportunity to study this issue because it is a rule-governed system with cognitive parallels to language (e.g., in syntactic processing), but without the complexities of lexical semantics (Patel, 2008). Dogs are an interesting choice of species to study because they are often raised in households where music is frequently heard. Furthermore, because domestic dogs are typically raised by humans (vs. by other dogs), much of their social attention and behavior is directed toward humans, which could be an important factor for developing sensitivity to human music (cf. ten Cate, Spierings, Huber, \& Honing, 2016).

In closing, I suggest that cross-species studies of music cognition, which have recently begun to attract growing interest (e.g., Fitch, 2015; Hoeschele et al., 2015; Patel, 2014), have much to offer the cognitive study of language evolution.

Acknowledgments I thank Richard Kunert, Bob Slevc, and two anonymous reviewers for helpful comments, and Paweł Kuśmierek for providing information on auditory short-term memory research in dogs and monkeys.

\section{References}

Andics, A., Gácsi, M., Faragó, T., Kis, A., \& Miklósi, Á. (2014). Voicesensitive regions in the dog and human brain are revealed by comparative fMRI. Current Biology, 24(5), 574-578.

Anrep, G. V. (1920). Pitch discrimination in the dog. The Journal of Physiology, 53(6), 367-385.

Bendor, D., \& Wang, X. (2005). The neuronal representation of pitch in primate auditory cortex. Nature, 436(7054), 1161-1165.

Collins, T., Tillmann, B., Barrett, F. S., Delbé, C., \& Janata, P. (2014). A combined model of sensory and cognitive representations underlying tonal expectations in music: from audio signals to behavior. Psychological Review, 121(1), 33.

Corrigall, K. A., \& Trainor, L. J. (2014). Enculturation to musical pitch structure in young children: Evidence from behavioral and electrophysiological methods. Developmental Science, 17, 142-158.
Fedorenko, E., Patel, A. D., Casasanto, D., Winawer, J., \& Gibson, E. (2009). Structural integration in language and music: Evidence for a shared system. Memory \& Cognition, 37, 1-9.

Fitch, W. T. (2013). Rhythmic cognition in humans and animals: distinguishing meter and pulse perception. Frontiers in Systems Neuroscience, 7(68), 10-3389.

Fitch, W. T. (2014). Toward a computational framework for cognitive biology: Unifying approaches from cognitive neuroscience and comparative cognition. Physics of Life Reviews, 11, 329-364.

Fitch, W. T. (2015). Four principles of bio-musicology. Philosophical Transactions of the Royal Society of London B: Biological Sciences, 370(1664). doi:10.1098/rstb.2014.0091

Flaugnacco, E., Lopez, L., Terribili, C., Montico, M., Zoia, S., \& Schön, D. (2015). Music training increases phonological awareness and reading skills in developmental dyslexia: A randomized control trial. PLOS ONE, 10(9), e0138715.

Gentner, T. Q., Fenn, K. M., Margoliash, D., \& Nusbaum, H. C. (2006). Recursive syntactic pattern learning by songbirds. Nature, 440, 1204-1207.

Kirchhofer, K. C., Zimmermann, F., Kaminski, J., \& Tomasello, M. (2012). Dogs (Canis familiaris), but not chimpanzees (Pan troglodytes), understand imperative pointing. PLOS ONE, 7(2), e30913.

Habib, M., Lardy, C., Desiles, T., Commeiras, C., Chobert, J., \& Besson, M. (2016). Music and dyslexia: A new musical training method to improve reading and related disorders. Frontiers in Psychology, 7, 26. doi: $10.3389 /$ fpsyg. 2016.00026

Heffner, H. E. (1983). Hearing in large and small dogs: Absolute thresholds and size of the tympanic membrane. Behavioral Neuroscience, 97, 310-318.

Hoeschele, M., Merchant, H., Kikuchi, Y., Hattori, Y., \& ten Cate, C. (2015). Searching for the origins of musicality across species. Philosophical Transactions of the Royal Society of London B: Biological Sciences, 370(1664). doi:10.1098/rstb. 20140094

Honing, H., Merchant, H., Háden, G. P., Prado, L., \& Bartolo, R. (2012). Rhesus monkeys (Macaca mulatta) detect rhythmic groups in music, but not the beat. PLoS ONE, 7(12), e51369.

Howell, T. J., Conduit, R., Toukhsati, S., \& Bennett, P. (2012). Auditory stimulus discrimination recorded in dogs, as indicated by mismatch negativity (MMN). Behavioural Processes, 89, 8-13.

Huber, L., Racca, A., Scaf, B., Virányi, Z., \& Range, F. (2013). Discrimination of familiar human faces in dogs (Canis familiaris). Learning and Motivation, 44(4), 258-269.

Jackendoff, R., \& Lerdahl, F. (2006). The capacity for music: What is it, and what's special about it? Cognition, 100(1), 33-72.

Koelsch, S., Gunter, T. C., Wittfoth, M., \& Sammler, D. (2005). Interaction between syntax processing in language and in music: An ERP study. Journal of Cognitive Neuroscience, 17(10), 15651577.

Koelsch, S., Kasper, E., Sammler, D., Schulze, K., Gunter, T., \& Friederici, A. D. (2004). Music, language and meaning: Brain signatures of semantic processing. Nature Neuroscience, 7, 302-307.

Koelsch, S., Rohrmeier, M., Torrecuso, R., \& Jentschke, S. (2013). Processing of hierarchical syntactic structure in music. Proceedings of the National Academy of Sciences, 110, 1544315448.

Kujala, M. V., Törnqvist, H., Somppi, S., Hanninen, L., Krause, C. M., Vainio, O., \& Kujala, J. (2013). Reactivity of dogs' brain oscillations to visual stimuli measured with non-invasive electroencephalography. PLoS ONE, 8(5), e61818.

Kuśmierek, P., Kowalska, D. M., \& Mishkin, M. (1999). Comparison of learning and performance of an auditory delayed matching-tosample in monkeys and dogs. Neural Plasticity, 6(Suppl. 1), 113114.

Krumhansl, C. L. (2015). Statistics, structure, and style in music. Music Perception, 33(1), 20-31. 
Kuśmierek, P., \& Kowalska, D. M. (1998). Effect of experimental setting on learning and performance of auditory delayed matching-tosample task in dogs. Acta Neurobiologiae Experimentalis, 58, 291-308.

Kunert, R., \& Slevc, L. R. (2015). A commentary on: "Neural overlap in processing music and speech.”. Frontiers in Human Neuroscience, 9, 330 .

Kunert, R., Willems, R. M., Casasanto, D., Patel, A. D., \& Hagoort, P. (2015). Music and language syntax interact in Broca's area: An fMRI study. PLoS ONE, 10(11), e0141069.

Kunert, R., Willems, R. M., \& Hagoort, P. (2016). Language influences music harmony perception: Effects of shared syntactic integration resources beyond attention. Royal Society Open Science, 3(2), 150685.

Lerdahl, F., \& Krumhansl, C. L. (2007). Modeling tonal tension. Music Perception, 24(4), 329-366.

Lima, C. F., \& Castro, S. L. (2011). Speaking to the trained ear: Musical expertise enhances the recognition of emotions in speech prosody. Emotion, 11(5), 1021.

Liu, F., Patel, A. D., Fourcin, A., \& Stewart, L. (2010). Intonation processing in congenital amusia: Discrimination, identification and imitation. Brain, 133, 1682-1693.

Müller, C. A., Schmitt, K., Barber, A. L. A., \& Huber, L. (2015). Dogs can discriminate emotional expressions of human faces. Current Biology, 25, 1-5.

Musso, M., Weiller, C., Horn, A., Glauche, V., Umarova, R., Hennig, J.,... Rijntjes, M. A. (2015). A single dual-stream framework for syntactic computations in music and language. NeuroImage, 117, 267-283.

Patel, A. D. (2003). Language, music, syntax and the brain. Nature Neuroscience, 6, 674-681.

Patel, A. D. (2008). Music, Language, and the Brain. New York: Oxford University Press.

Patel, A. D. (2014). The evolutionary biology of musical rhythm: Was Darwin wrong? PLoS Biology, 12(3), e1001821.

Patel, A. D., Peretz, I., Tramo, M., \& Labreque, R. (1998). Processing prosodic and musical patterns: A neuropsychological investigation. Brain and Language, 61, 123-144.

Peretz, I., Vuvan, D., Lagrois, M. É., \& Armony, J. L. (2015). Neural overlap in processing music and speech. Philosophical Transactions of the Royal Society of London B: Biological Sciences, 370(1664). doi:10.1098/rstb.20140090

Ratcliffe, V. F., \& Reby, D. (2014). Orienting asymmetries in dogs' responses to different communicatory components of human speech. Current Biology, 24(24), 2908-2912.

Ravignani, A., Sonnweber, R. S., Stobbe, N., \& Fitch, W. T. (2013). Action at a distance: Dependency sensitivity in a New World primate. Biology Letters, 9(6). doi:10.1098/rsbl.2013.0852

Rohrmeier, M. (2011). Towards a generative syntax of tonal harmony. Journal of Mathematics and Music, 5, 35-53.

Rosati, A. G., Santos, L. R., \& Hare, B. (2010). Primate social cognition: Thirty years after Premack \& Woodruff. In M. L. Platt \& A. A. Ghazanfar (Eds.), Primate neuroethology (pp. 117-143). New York: Oxford University Press.

Saffran, J. R., Aslin, R. N., \& Newport, E. L. (1996). Statistical learning by 8-month-old infants. Science, 274, 1926-1928.

Saffran, J. R., Johnson, E. K., Aslin, R. N., \& Newport, E. L. (1999). Statistical learning of tone sequences by human infants and adults. Cognition, 70(1), 27-52.
Schachner, A., Brady, T. F., Pepperberg, I. M., \& Hauser, M. D. (2009). Spontaneous motor entrainment to music in multiple vocal mimicking species. Current Biology, 19(10), 831-836.

Scott, B. H., Mishkin, M., \& Yin, P. (2012). Monkeys have a limited form of short-term memory in audition. Proceedings of the National Academy of Sciences, 109(30), 12237-12241.

Slevc, L. R., \& Patel, A. D. (2011). Meaning in music and language: Three key differences: Comment on "Towards a neural basis of processing musical semantics" by Stefan Koelsch. Physics of Life Reviews, 8, 110-111.

Slevc, L. R., Rosenberg, J. C., \& Patel, A. D. (2009). Making psycholinguistics musical: Self-paced reading time evidence for shared processing of linguistic and musical syntax. Psychonomic Bulletin and Review, 16, 374-381.

Song, X., Osmanski, M. S., Guo, Y., \& Wang, X. (2016). Complex pitch perception mechanisms are shared by humans and a New World monkey. Proceedings of the National Academy of Sciences, $113(3), 781-786$

Stewart, L., MacLean, E. L., Ivy, D., Woods, V., Cohen, E., Rodriguez. K....Hare, B. (2015). Citizen science as a new tool in dog cognition research. PLOS ONE, 10(9), e 0135176.

ten Cate, C., \& Okanoya, K. (2012). Revisiting the syntactic abilities of non-human animals: Natural vocalizations and artificial grammar learning. Philosophical Transactions of the Royal Society of London B: Biological Sciences, 367(1598), 1984-1994.

ten Cate, C., Spierings, M., Hubert, J., \& Honing, H. (2016). Can birds perceive rhythmic patterns? A review and experiments on a songbird and a parrot species. Frontiers in Psychology, 7, 730. doi:10. 3389/fpsyg.2016.00730

Thompson, W. F., Schellenberg, E. G., \& Husain, G. (2004). Decoding speech prosody: Do music lessons help? Emotion, 4, 46.

Tillmann, B., Koelsch, S., Escoffier, N., Bigand, E., Lalitte, P., Friederici, A. D., \& von Cramon, D. Y. (2006). Cognitive priming in sung and instrumental music: activation of inferior frontal cortex. Neuroimage, 31(4), 1771-1782.

Törnqvist, H., Kujala, M. V., Somppi, S., Hanninen, L., Pastell, M., Krause, C. M., ... Vainio, O. (2013). Visual event related potentials of dogs: a non- invasive electroencephalography study. Animal Cognition, 16(6), 973-982.

Trainor, L. J., \& Trehub, S. E. (1992). A comparison of infants' and adults' sensitivity to western musical structure. Journal of Experimental Psychology. Human Perception and Performance, $18(2), 394$

Tillmann, B., \& Bigand, E. (2015). Response: A commentary on: "Neural overlap in processing music and speech.". Frontiers in Human Neuroscience, 9, 491.

Van de Cavey, J., \& Hartsuiker, R. J. (2016). Is there a domain-general cognitive structuring system? Evidence from structural priming across music, math, action descriptions, and language. Cognition, 146, 172-184.

Yuan, J., Rosenberg, J. C., \& Patel, A. D. (2016). An empirical study of dogs howling to music. Proceedings of the 14th International Conference on Music Perception \& Cognition, July 2016, San Francisco. (in press)

Zatorre, R. J., \& Salimpoor, V. N. (2013). From perception to pleasure: Music and its neural substrates. Proceedings of the National Academy of Sciences, 110(Suppl. 2), 10430-10437. 